\title{
Technical Session
}

Information and Power

Point Presentation Guidelines

IEEE IAS Annual Meeting 2006 


\section{This file contains:}

- General session information (2 pages)

- Background and text color guidelines (2 pages)

- Font Guidelines (1 page)

- Guidelines for graphs and figures (1 page)

- A Sample presentation (5 pages)

- A sample "bad" figure (2 pages) 


\section{General Session Information}

- All presentations are scheduled for $\mathbf{3 0}$ minutes including questions

- Specific details can be arranged with your session chair before the conference or at the author's breakfast on the morning of your presentation

- Computer projection equipment and a computer will be provided in every session room

- Always a good idea to bring your own laptop (as backup) whenever possible

- Only Microsoft Power Point presentation software should be used-other formats are not likely to be supported 


\section{General Session Information}

- It is your responsibility to

- Coordinate the transfer of your presentation with your session chair for installation on the computer in the session room

- A common approach is to bring the presentation to the conference on a CD or memory stick-consider bringing a backup copy as well

- Verify that your presentation does not use fonts or other features that are not installed on the computer in the session room 


\section{Poor Color Choices}

- This combination will be impossible to see - no contrast

-This combination can't be read by people who are color blind
- This combination has good contrast but this dark back-ground will blacken the room too much and if your font is too thin, it won't be visible 


\section{Fonts}

- Use ARIAL "Bold"

- Some fonts project poorly because line width is too thin

- Times

- Bookman

- Americana

- Use as large a font as possible

-Titles: 48-54

- Main text titles: 32

- Smallest text lines: 24

- Anything below 24 is too small 


\section{Graphs and Figures}

- Don't make graphs complicated

- The audience can't read a graph with too much information

- The audience can't read a graph with lots of thin lines

- The audience can't read a graph with dotted, dashed, or other specialty lines unless they are very bold and thick. 


\section{Sample Presentation}

- Title Slide

- May contain logo

- Text Slides

- Do not contain commercial or corporate logos

- Schematic Slide 


\section{A 2.5V, 333MHz Embedded Memory with Differential I/O}

Joel Stevenson, John Johnson, Skip Douglas and Jack Taylor High Performance Design Center Dallas, Texas

Your Logo Mere 


\section{Outline of Presentation}

- Motivation for Work

- Overview and Design Requirements

- Differential I/O Circuits

- Special Purpose Circuits

- READ/WRITE Mechanism

- Measured Results

- Conclusion 


\section{Differential I/O Circuits}

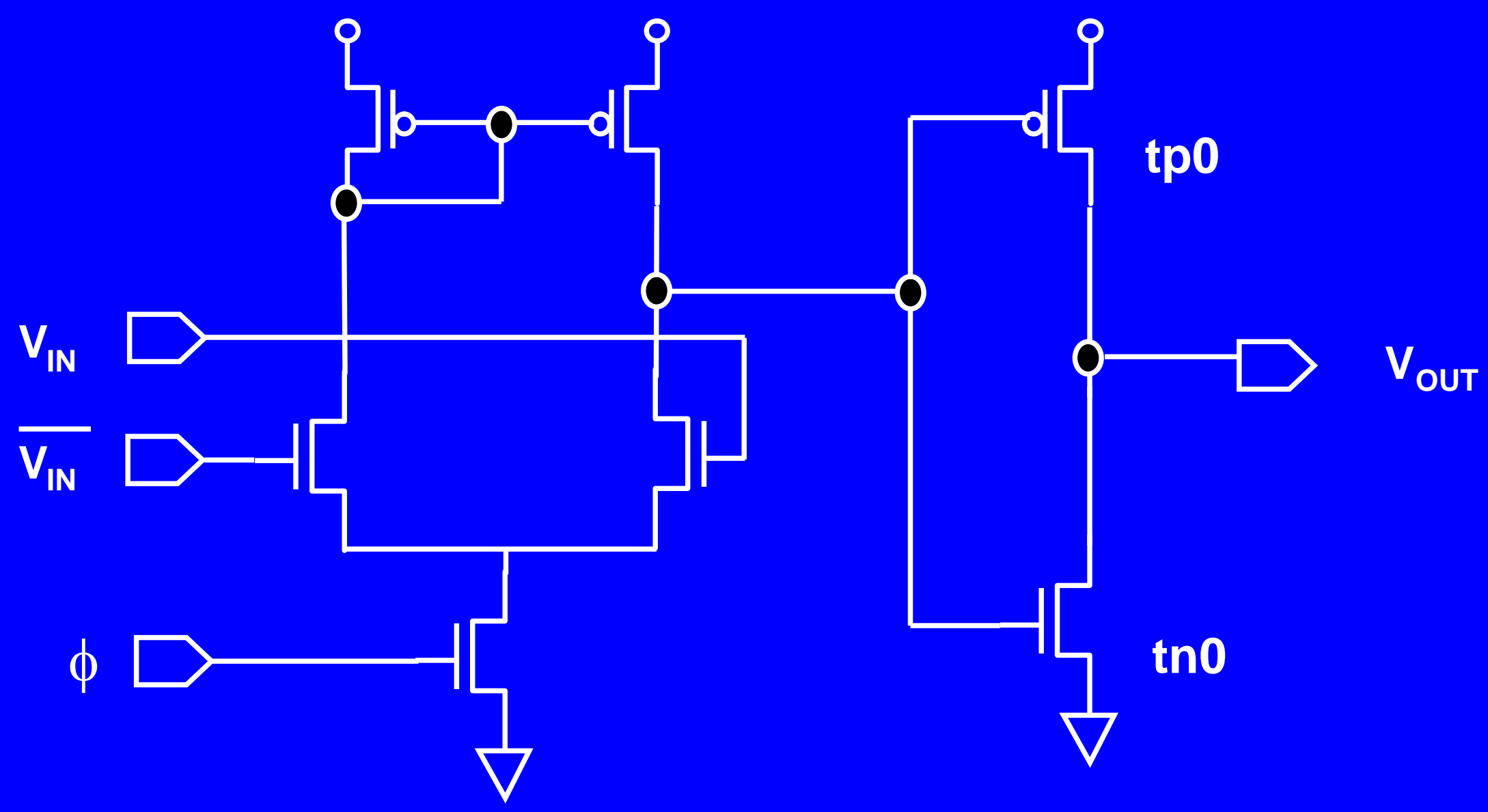

-Text and drawing are visible to everyone 


\section{Conclusion}

- Novel differential I/O technique reduces output driver latency $\mathbf{2 5 \%}$

- New charge-sharing sense-amplifier improves access times

- READ/WRITE circuit techniques allow further speed improvements

- Measured access times at $85^{\circ} \mathrm{C}$ were demonstrated above $100 \mathrm{MHz}$

- Embedded custom array design achieves 10 ns cycle at less than $5 \mathrm{~W}$ in $44.5 \mathrm{~mm}^{2}$ area 


\section{"Bad" Figure Example on next page}

- Too busy

- Too many lines

- Fonts too small 


\section{This Figure is way too busy}

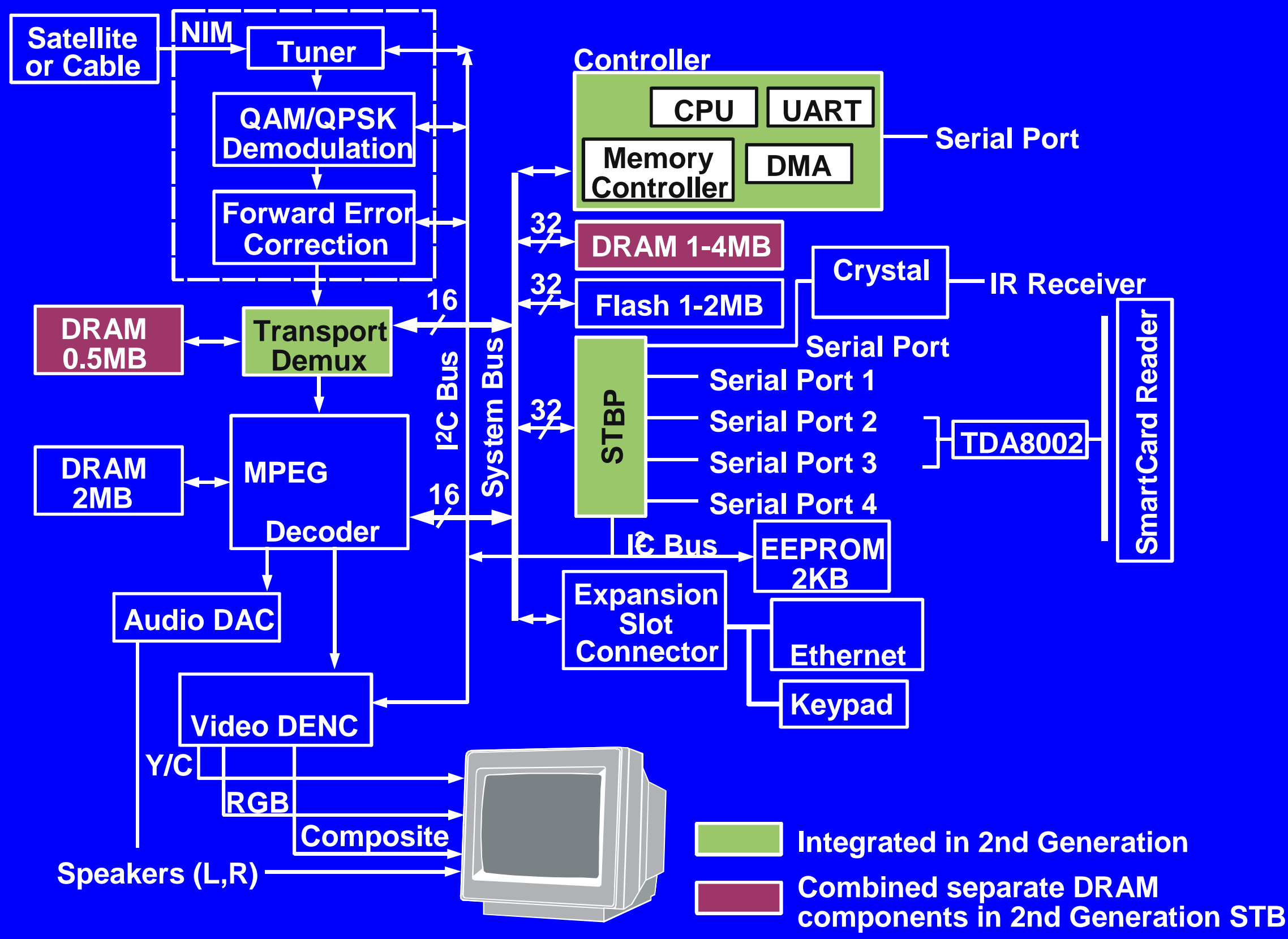

